\title{
Survey on Attitude Towards New Management Mode of Linguistic Landscape Programs in Chinese University Language Resources and its Decision Tree Analysis
}

\author{
Bin $\mathrm{Lu}^{1}$, Eksiri Niyomsilp ${ }^{2}$ \\ ${ }^{1}$ Ph.D., School of Management, Shinawatra University. Thailand; Foreign Languages School, Luoyang Normal \\ University. China \\ ${ }^{2}$ Ph.D., School of Management, Shinawatra University, Thailand \\ Correspondence: Bin Lu, Ph.D., School of Management, Shinawatra University. Thailand; Foreign Languages School, \\ Luoyang Normal University. China.
}

Received: July 20, 2021

doi:10.5430/elr.v10n4p1
Accepted: September 16, 2021

Online Published: October 3, 2021

URL: https://doi.org/10.5430/elr.v10n4p1

\begin{abstract}
In order to survey the attitudes towards the different social participants of intelligent collaboration program on linguistic landscape in Chinese university language resources and university technology resources, find effective methods and applied path to develop new management mode in Chinese university language education and professional training quality of foreign language majors, this article is to carry out attitude survey towards new management mode, namely Government-Industry-University-Research management mode, which can solve the dissatisfied responses for service competence of foreign major students in their real profession field and the implementation difficulty of Standards which issued for the translation revision program on linguistic landscape for local city images construction. Based on the perspective of intelligent diagnosis and intelligent collaboration, this article explores the applied path model on quality monitoring system of linguistic landscape in the aspects of target orientation, content index, implementation process and intelligent collaboration system, which has an important enlightenment and reference role for improving the national quality monitoring system of linguistic landscape by the mix research of qualitative and quantitative methods. And it describes the hierarchical comprehensive evaluation index for the construction of quality monitoring system on linguistic landscape with two steps: 1) the first step is to use analytic hierarchy process (AHP) to decompose the quality monitoring of linguistic landscape into multi-level and multi-dimensional index system, model and quantify the implementation process of quality monitoring, and to construct the first and second-class index system to solve the current problems of quality monitoring and quality improvement; 2) the second step is to use decision tree(DA) analysis to view the evaluation and suggestions of participants in relevant fields on various indicators at all levels from collect feedback results, ensure scientific and reasonable determination of quality monitoring indicators through supplement and scientific revision. The conclusion is that: 1) The new management mode of linguistic landscape programs will benefit the education quality of foreign language majors and improve their service function for the society development. 2) The new management mode will benefit the government department on language technology resources, linguistic technology platform, intelligent collaboration and talents mapping of local city development.
\end{abstract}

Keywords: education management mode, university language resources, intelligent collaboration, analytic hierarchy process, decision tree analysis

\section{Introduction}

According to the current problems of foreign language education in Chinese university management, including administrative domination management, lacking of innovation scientific model and so on, many previous research results concentrated in the macro analysis on the requirements of education management reform and strategy initiatives mostly, but the practical reform method in universities management reform on foreign language education, the specific implementation steps and standards, especially the new management mode which carry out Government-IndustryUniversity-Research cooperation program to improve teaching quality management have not been specifically discussed. This article aims to promote the innovation of foreign language education management in Chinese 
universities with the implementation methods and pilot design of experimental research through the new program management mode of quality monitoring system on linguistic landscape. The research methods are designed by survey investigation and experimental research on the construction path and applied method of quality monitoring system on linguistic landscape, and analyzes the purpose, plan, steps, methods, assessment and evaluation of experimental research on education management mode, namely Government-Industry-University-Research management mode, which is based on the development and diversification of university language resources and foreign language students' evaluation training program. It also puts forward a new education management mode of the collaboration cultivation on decentralization, outstanding characteristics, school-enterprise combination and order training domination in university education management, so as to provide a reference for the reform path and strategy of education management on university foreign language majors through carrying out turning the traditional classroom teaching mode and traditional assessment mode to highlight the serving for the country and the government at the same time.

Government-Industry-University-Research Management Mode is a matter of new management mode in Chinese university students training programs which is beneficial to the improvement of students profession competence, university education quality and local city cultural development, it differs from the previous students training programs and covers at least four elements in collaboration development in education management reform, namely local government departments take part in the university education management from the consideration of construction of local culture and local city development, local companies or enterprises will take part in the university education management from the consideration of industry requirement on language service, university students take part in the university education management from the consideration of improving the profession gap between the university majors and society development, university teachers and scientific researchers take part in linguistic professional studies and social cultural development. This new management mode not only starts the new collaboration reform of university language resources but also starts the new intelligent technology resources of society development. Through the attitude survey of implementation construction methods on new management mode of "Government-IndustryUniversity-Research", three aspects of student training, scientific research, and industrial transformation are organically integrated, giving full play to their respective advantages, using scientific research to drive discipline construction and program innovation of student professional training, and using language industrial transformation to give full play to the value of scientific research achievement of Chinese university language resources. At the same time, further feedback of this experimental research and promotion of scientific research provide a practical platform for student professional training, combined with national guidance, to achieve rapid development of disciplines, scientific research, and industry service quality. This article is to highlight the turning of quality monitoring system among Chinese universities from university students individuals to university language resources system and language technology system. This is also the turning of experimental program from ordinary education assurance to all member system assurance in university quality management.

This research carries out the two rounds of survey, namely, The first round of survey on the subject of GovernmentIndustry-University-Research mode, mainly aims at the attitudes of different social groups of Government-IndustryUniversity-Research mode towards the quality of local linguistic landscape, as well as the views and suggestions on the construction of quality monitoring system of linguistic landscape in Chinese university, and test this experimental research is acceptable or not. The second round of survey on the subject of construction methods of quality monitoring system on linguistic landscape, mainly aims at the attitudes of construction methods of quality monitoring system on linguistic landscape, such as the function, effectiveness, content, index and path of the construction quality monitoring system, obtained the survey data, and established the relevant index system, to survey the attitude towards intelligent collaboration in new management reform mode.

\subsection{Research Basis of New Management Mode}

From the macroscopic level, linguistic landscape research is one of the emerging fields of sociolinguistics and applied linguistics research, this is the first time to discuss linguistic landscape revision from university technology resource and university language resource. This research gives a comprehensive description of the function of linguistic landscape program for students professional competence, the common understanding of this research topic, and the related reference sampling on construction of quality monitoring system for local city internationalization. The aim is to systematically master the technology resources and intelligent collaboration of quality monitoring system on linguistic landscape, to present an overview of the outlooks of the translation quality of local culture, to improve the quality of all kinds of levels of local city internationalization.

From mesoscopic level, there are a series of Standards and References issued by the research field between the experts team and government departments. This research gives a comprehensive description and different participants feedback 
from the earlier statement of public response for Standards or references on linguistic landscape revision, and this experimental research of carrying out this new Government-Industry-University-Research management mode. It is the time to investigate the attitude towards participants in different profession fields, government officials who are in charge of linguistic landscape programs for local city development and who are in charge of construction the international image of local city, the local universities which have many language resources and talents to improve the quality of linguistics landscape, the local companies which are urgent to start the overseas markets and are urgent to construct their own international brand, local individuals who can be the great power of the data collection on linguistic landscape revision program, English majors and translators of local university who are likely to investigate the acceptable agreement on the new Standards and References issued during these 3 years and find a new path to promote their service quality from professional contribution.

From microscopic level, it is really difficult to make an common agreement on the understanding of the meaning, connotation, classification and main function of linguistic landscape programs from the perspective of intelligent monitoring system, not only for the university students and university language resources management, but also the social participants, quality technological and intelligent platforms. This research pays attention to the attitude towards quality monitoring platform and intelligent cooperation modes of different social participants who are active to improve the translation quality of linguistic landscape for local internationalization and develop diversity management of linguistic landscape resources in Chinese university. The comparison between the earlier statement of the lacking of effective methods and channels to construct the intelligent system on quality monitoring and connecting specific Big Data, and the later statement of intelligent collaboration on quality monitoring system. This research puts forward the construction of linguistic landscape technology, stratified sampling, with collection, revision and investigation to Luoyang city, a famous ancient capital and tourist city in China, it full of varied public signs with foreign languages as the pilot research objective, to explore how to develop and make use of language resources, especially the new kind of soft power of university language resources and language talents resources for local city development, and the new construction methods of sustainable development of linguistic landscape monitoring system and its marketing and industrial development.

\subsection{Research Significance of New Management Mode}

The service function of Chinese university education management refers to the responsibilities and functions of university students and teachers who make their contribution to serving for society and country. The service function of the university students is always to be forgotten in university education when too much concern on the academic grades and examination marks. The teaching focus of foreign language majors is to training the major skills for graduation and new job market, but the service of university students only come from the personal willingness and personal design, there is no scientific training mode or training discipline which can connect with the whole courses of foreign language training and the lack of valuing on the university language resources. This new experimental research not only includes university language information, consultation, coordination, funding and other projects provided by the state, society and local city, but also the new participant management reform of society development as an important means of macro-control of university education quality, which provides order-training workshop and school administrators transformation for the bridge between the university students and society. And many countries pay attention to the establishment of large information consulting centers to provide rich statistical data and educational materials for local education and carry out various educational consultation. The management of foreign language education in universities is of great significance to improve the level of foreign language teaching, language resources management, teaching quality and university running efficiency, to realize the scientific and standardized improvement of foreign language education, to ensure the quality of the educational goal on foreign language personnel training, and to improve the effect of foreign language teaching and learning. At present, it is necessary to carry out all-round effective management of foreign language education resources, process informatization management on foreign language education, comprehensive information process on foreign language education, network resource database on foreign language education, scientific research informatization and foreign language laboratory resources, so as to realize the optimization and integration of foreign language education resources. 


\subsection{Experimental Research}

\section{Pre-test:}
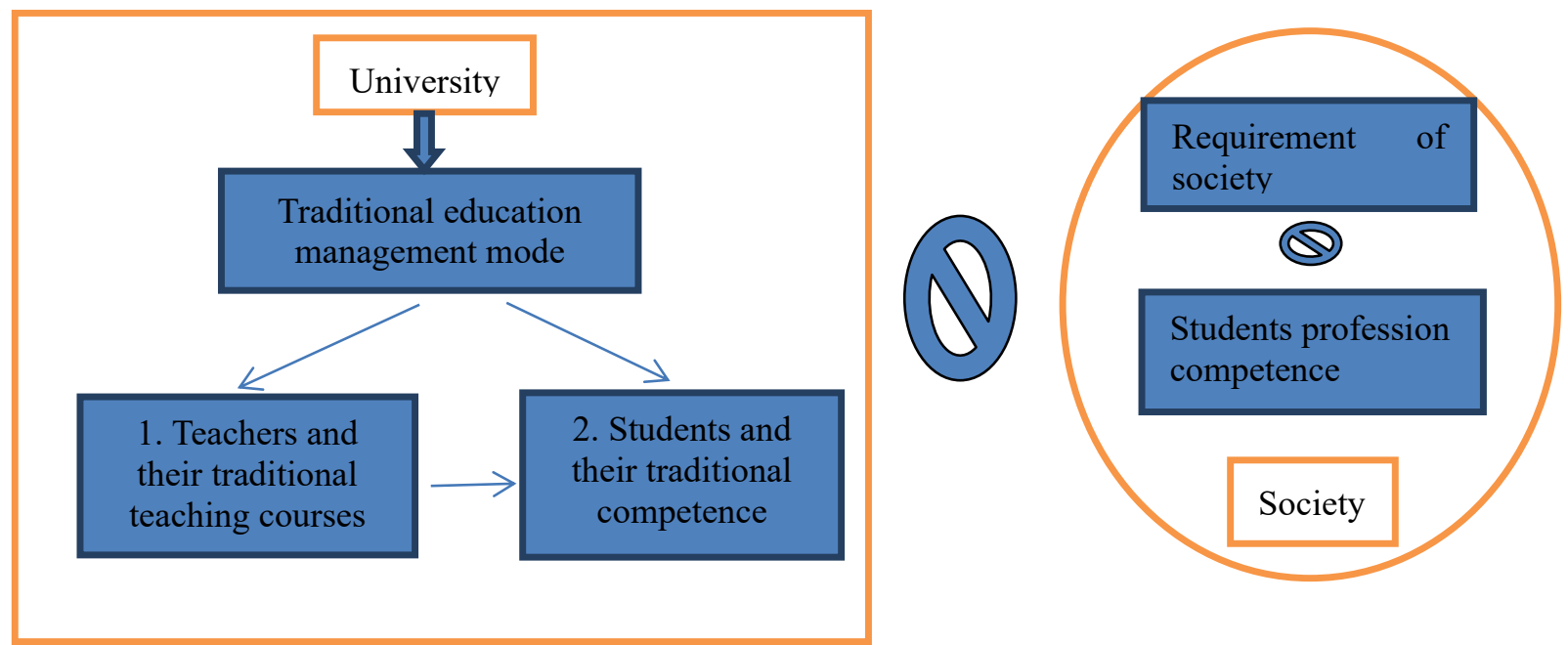

Figure 1. Pre-test Research Subjects

\section{Post-test:}

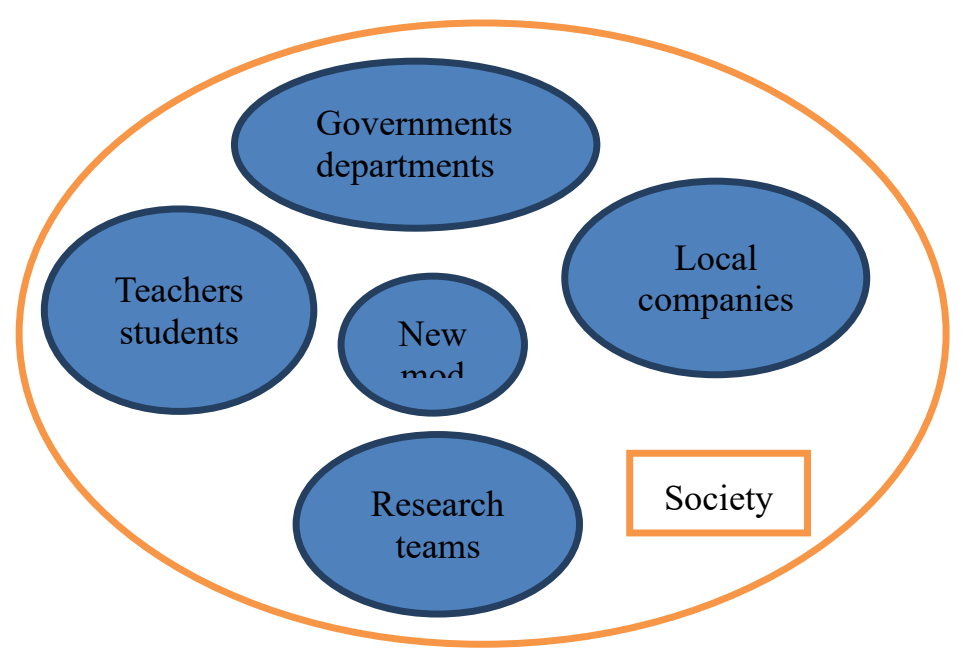

Figure 2. Post-test Research Subjects

\section{Literature Review of Intelligent Collaboration}

Collaboration is an activity that individuals cooperate with each other in order to achieve a certain goal or improve work efficiency. The "intelligent collaboration" of this university language resources is the key term of collaboration technology platform on quality monitoring system, the following are main aspects of this perspective.

\subsection{Intelligent Collaboration}

In the coming $5 \mathrm{G}$ era, online resources will become the foundation of existence for each cell of local city, not only local companies but also local universities. The core feature of future organizations is people-centered intelligent collaboration, and the premise of intelligent collaboration is online resources. Human centered intelligent collaboration includes the intelligent collaboration among people, people and things. Among them, the intelligent collaboration among people is actually to create a deep integration of communication and collaboration in one field, eliminate irrelevant information and improve concentration. The intelligent cooperation between people and things is to turn 
tedious into simple. The problems of university language resources are neglected and their social participants statement is too lower, these facts can not match their fast developing period and society requirements. This research is to call for notice on intelligent collaboration of university language resources.

\subsection{Intelligent Collaboration in Education Research}

In education level, it is proposed to cultivate intelligent economy, build intelligent society and intelligent education with some new policies and measurement, such as New Generation of Artificial Intelligence Development Plan of the State Council in 2017, and Education Informatization 2.0 Action Plan in 2018, which proposes to promote intelligent education and explore new ubiquitous, flexible and intelligent teaching environment construction and application mode vigorously. Intelligent education is to adapt to the development of education in the intelligent environment. With the development of information technology, especially intelligent technology, it has become another practice hot spot of "Internet plus" education reform (Yuan Gao, Ronghuai Huang, 2017). Intelligence education is not only to use artificial intelligence technology to assist education, but also to cultivate students' individual intelligence development. In the era of artificial intelligence, intelligence will eventually evolve into a hierarchical structure of "machine intelligence plus human" and human-machine cooperation intelligence dominated by human life. That is, the basis of humancomputer cooperation, such as computational thinking, collaboration support, computational intelligence, perceptual intelligence, cognitive intelligence, collaborative interface and intelligent environment. This intelligent environment is including intelligent system, intelligent platform, intelligent media, and this research is a matter of intelligent monitoring system on linguistic landscape quality. And collaboration subject covers cognitive intelligence, emotional intelligence, interest intelligence and innovation intelligence. In the era of intelligent education, the professional form of university teachers will involve human-computer collaboration work from different levels. The teachers will focus on the professional ability that highlights the characteristics of society life (Yonghai Zhu, Hui Liu, et al., 2019), provide high-end society service quality; promote the intelligent education of human-computer collaboration, explore the overall meaning of life quality. University teachers and students will jointly understand the life practice to form a new professional form level in university resources management. Therefore, in addition to the application in teaching, intelligent collaboration is also reflected in the university's intelligent applications such as classification and recommendation of language technology resources and university intelligent technology resources.

On the practical example of description the concept and form of cognitive extension brought by artificial intelligence, Haihong Meng puts forward the analysis framework of the cooperation between librarians and artificial intelligence, and discusses the core characteristics of the cooperation between artificial intelligence and librarians. With the support of artificial intelligence, the collaboration process of librarians is more natural and smooth, the collaboration objects of librarians are more diverse, and human-computer collaboration becomes the norm. With the continuous improvement of the ability of artificial intelligence to assist librarians to solve problems, artificial intelligence will gradually replace the circulation librarians, reading librarians, cataloging librarians, and even reference librarians and subject librarians in traditional libraries, and become the most important service implementer in libraries (Haihong Meng, 2020). Yang Li also believes that promotion and application of intelligent technology and different kinds of new equipment, the transformation of human thinking and cognitive style will be promoted. In the foreseeable future, human-computer collaboration thinking will be accepted, and it will help people improve their cognitive speed, control complex situations, process massive amounts of information, and even expand their cognitive limit (Li Yang, 2017). According to the data collection of intelligent diagnosis, it puts forward that "open source community" should be used to improve the efficiency of APP software development and strengthen the government's digital supervision ability on the supply side of sports manufacturing (Shu Liang and Yimin Wang, 2016). In order to greatly improve the work efficiency, it puts forward high requirements for the automatic sorting system. How to deal with a large number of logistics packages efficiently and how to sort and transfer them at the fastest speed are inseparable from the intelligence and cooperation of automatic sorting equipment. Using automatic fast sorting technology to replace a large number of manual sorting not only reduces the labor cost, but also greatly improves the efficiency and accuracy of sorting operation (Ying Xu, 2020).

This study is to select the survey research perspective to test the attitude towards quality monitoring system of linguistic landscape and to build the intelligent collaboration between university language resources and society technology platforms. The aims are not only to solve the translation quality problem of linguistic landscape in local city, but also to carry out a new kind of management reform mode in university education for foreign language majors, and the new data resource management of university technology resources. 


\section{Research Design}

This survey study on Government-Industry-University-Research management mode which aims at investigating the different attitudes towards the construction of quality monitoring system on linguistics landscape among social participants in Chinese university resources, and reaching social cognition on the applied construction methods of sustainable development of university education training of linguistic landscape program, quality monitoring system on linguistic landscape from the perspective of education management. It has great significance for improving the whole quality level of linguistic landscape translation and linguistic landscape resources, promoting the innovation and development of Chinese university resources and technology. The experimental research costs not only the manpower and material resources, but also the university language resources which can support the Artificial Intelligence, Big Data and Cloud Computing.

\subsection{Research Problems}

1. What's the attitude towards effective methods and applied path to develop this new education management mode of Chinese university language resources and intelligent collaboration resources?

2. What's the attitudes towards function and contribution of experimental research on quality monitoring system of linguistic landscape in management and development of Chinese university language resources from analytic hierarchy process analysis and decision tree analysis?

3. What's the attitudes towards the new management reform of Government-Industry-University-Research mode among these different participants? And what's the suggestion for the policy-maker on future policy design?

\subsection{Research Methods}

\subsubsection{Experimental Research}

The earlier situation of education management problems in Chinese foreign language education is the fact that the lack of innovation of education reform both in teaching and learning, the dissatisfied and questioned comments on the service quality in different social profession field of foreign language students, the lack of the new management mode to call on all the teachers and students to participate in teaching practice training, the lack of new collaboration mode which can construct the international image of local city, the lack of new technology platform which can make rational utilization of university language resource and university technology resource. This experimental research is to construct the foundation of new education reform mode which will carry out the new management innovation both in university resources and in society resources by setting experimental objectives, participating in the relevant links and processes of university research community deeply, and exploring the root problems of mobilizing the enthusiasm and creativity of cultivating students' service competence.

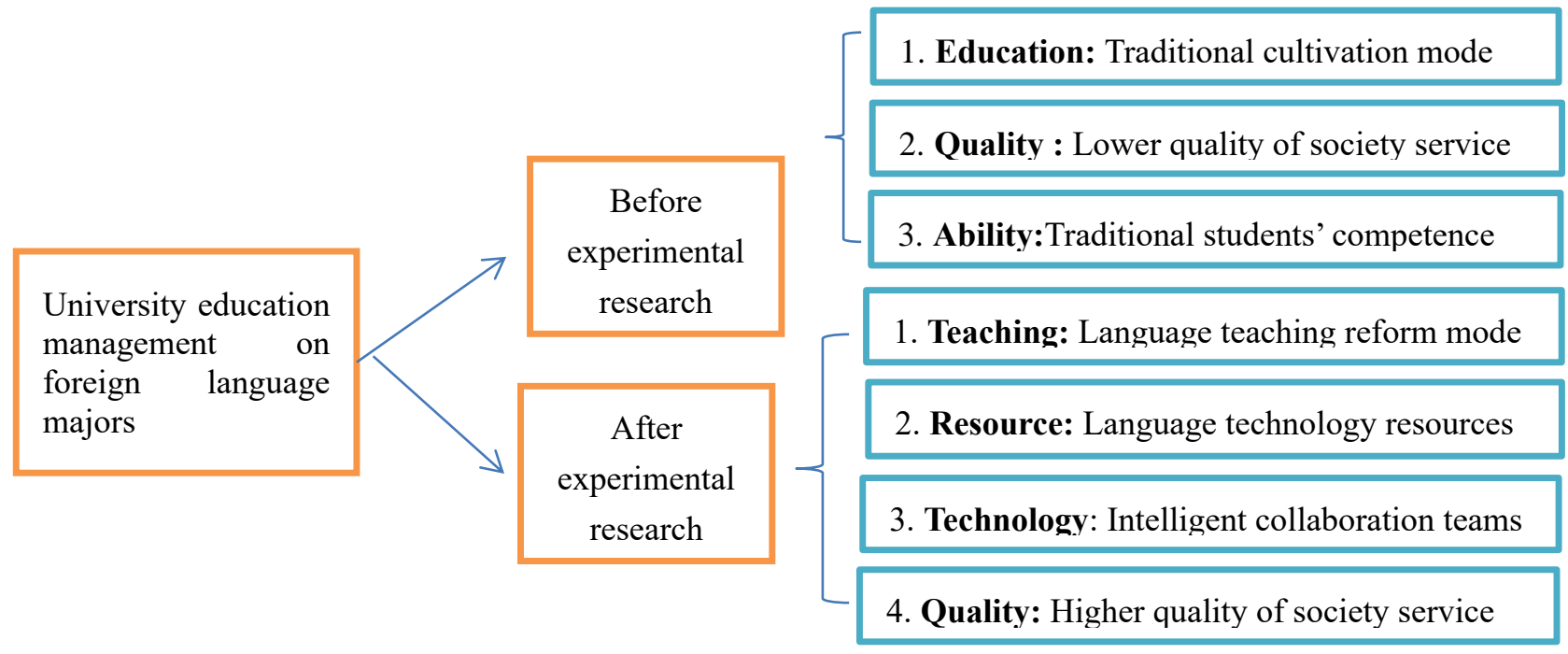

Figure 3. The Before and The After of Experimental Research

\subsubsection{Survey Research}

Based on the construction of linguistic landscape quality monitoring, this study adopts two rounds of attitude survey (Bin Lu, 2019). The first attitude survey mainly aims at the attitudes toward different social participant groups of 
Government-Industry-University-Research mode and its community teams towards the quality of local linguistic landscape, as well as the views and suggestions on the construction of quality monitoring system of linguistic landscape in Chinese university, and test this experimental research on new management mode is acceptable or not; the second survey mainly visited and investigated representatives of different social groups about the construction of quality monitoring system of linguistic landscape, such as the function, effectiveness, content, index and path of the construction quality monitoring system, obtained the survey data, and established the relevant index system after analysis and collation, to survey the attitude and construction method of intelligent collaboration in new management reform mode.

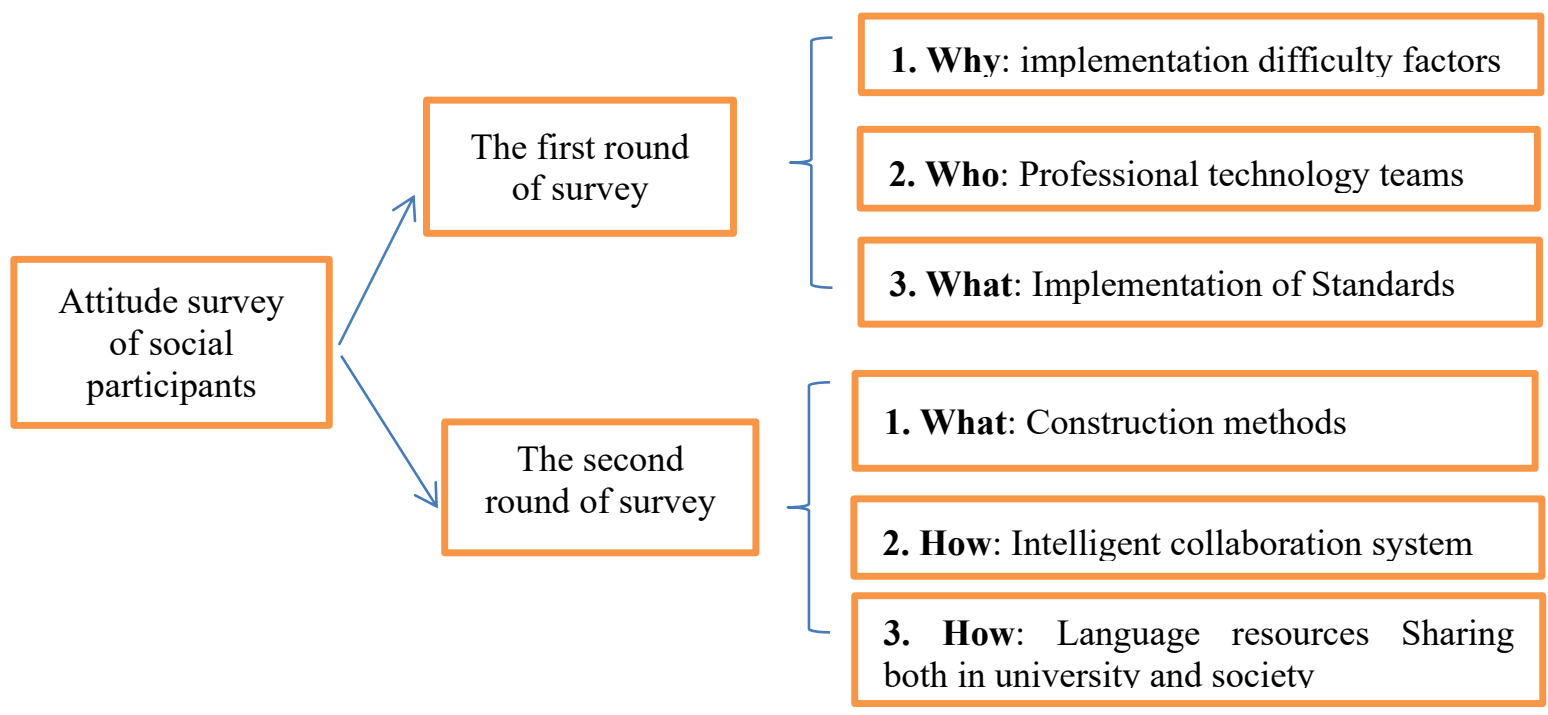

Figure 4. The Two Rounds of Survey

\subsubsection{Analytic Hierarchy Process Analysis}

The analytic hierarchy process (AHP) analysis is implemented to evaluate the quality monitoring indicators of intelligent collaboration system in language technology resources both in university and society, and rank the importance of the new management mode of linguistics landscape in university education for foreign language major. Four criteria considered in the AHP include university technology platform, government department support, local company participants and talents mapping. The analytic hierarchy process analysis is to realize the institutionalized, standardised and informationized of new management mode of university language resources and these four criteria will be discussed in part 4. 
Table 1. Evaluation Index System of Quality Monitoring Program on Linguistic Landscape

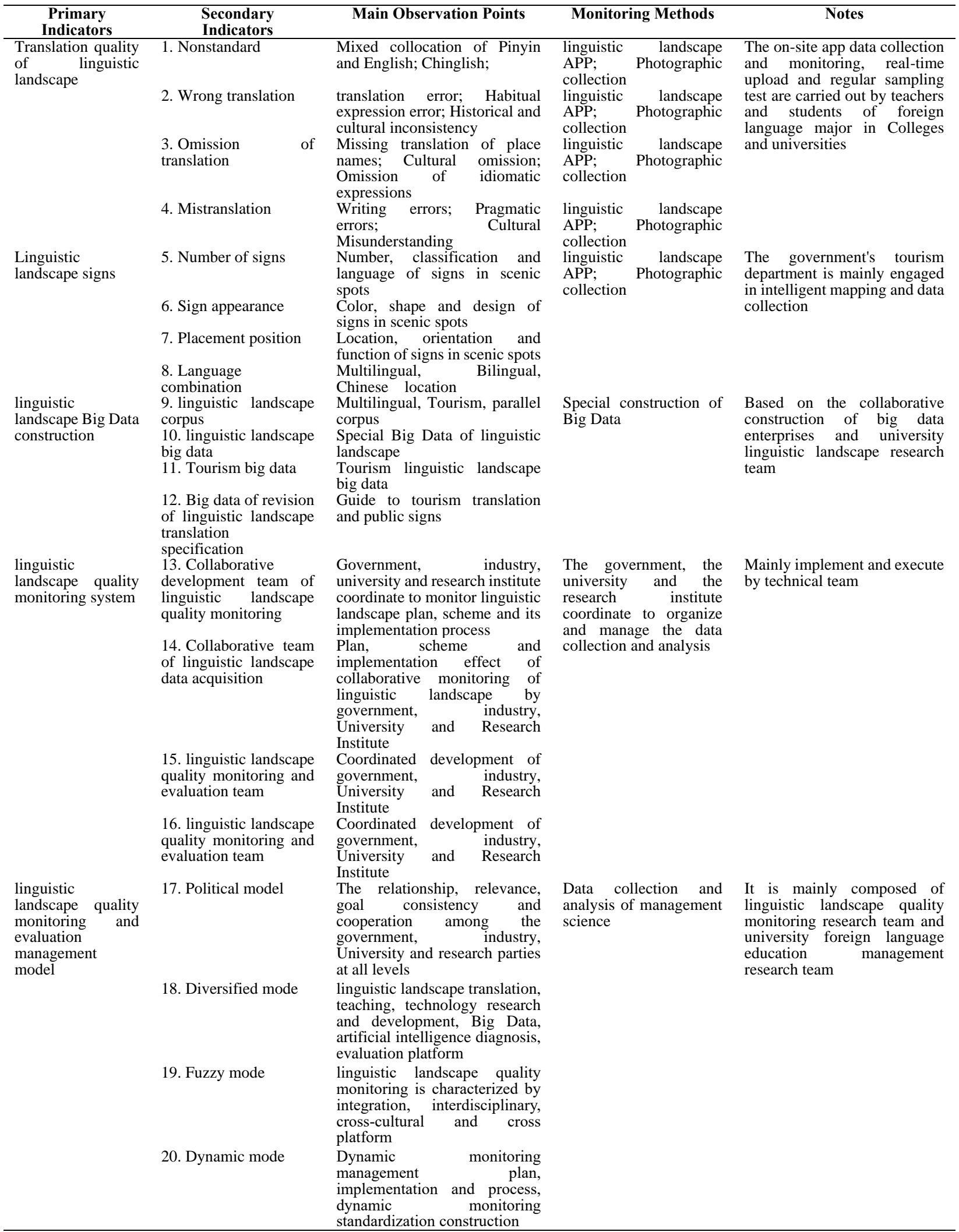




\subsubsection{Decision Tree Analysis}

This study is demonstrated that the potential benefits and risks among the social participants survey by decision tree analysis approach. With systematical and appropriate data and figures, it can effectively show where linguistic landscape program in university language resource is most needed, and it will be helpful for future adjustment on university education management and policy-maker of government department. The decision tree analysis will be demonstrated in part 4 from the different participants, such as government department, local companies and local universities.

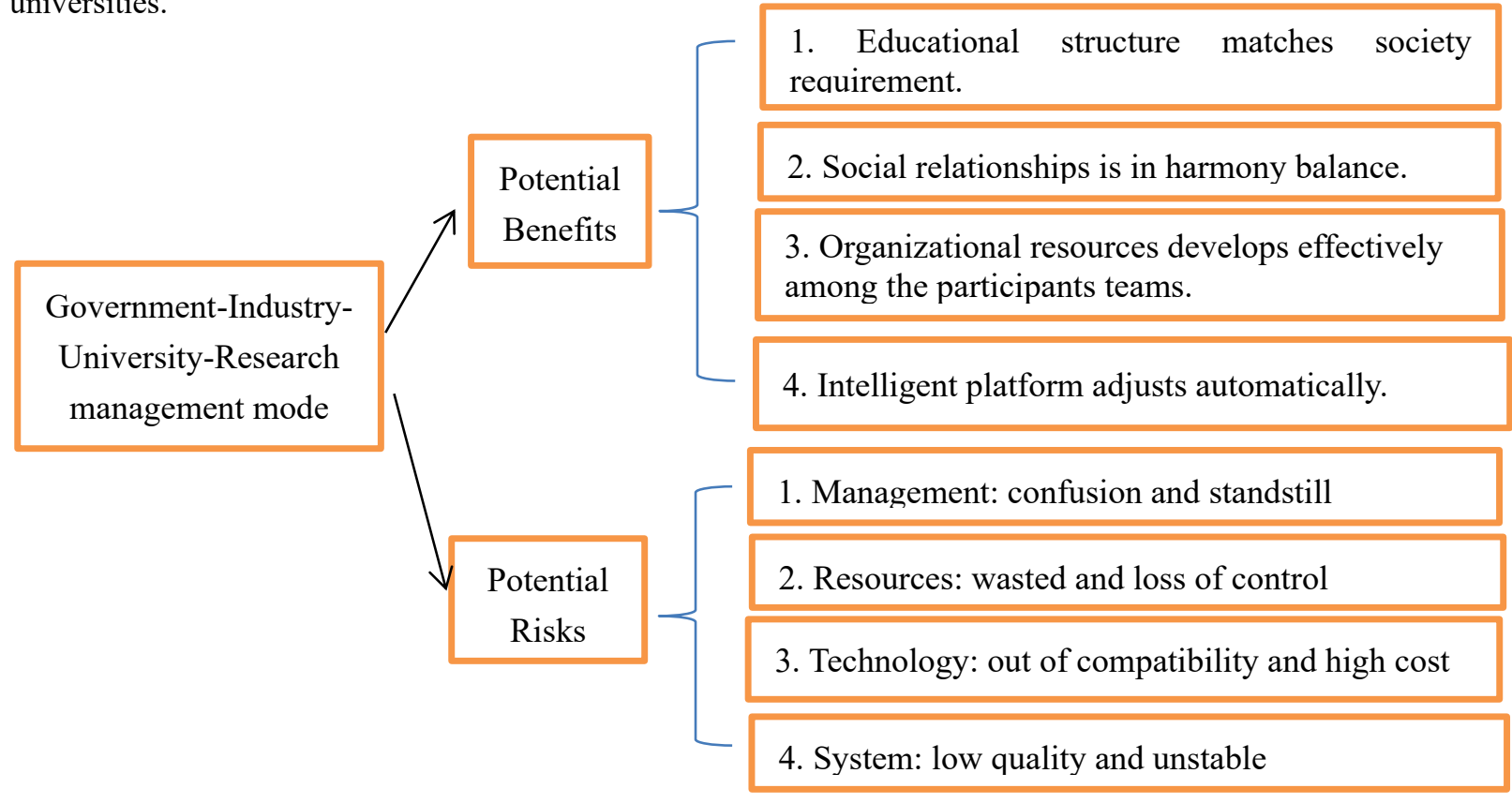

Figure 5. The Decision Tree Analysis of New Management Mode

\section{Data Analysis and Discussion}

This study analyzes and explains the data of experimental research of Government-Industry-University-Research management mode in foreign language education of Chinese university with Analytic Hierarchy Process (AHP) calculate data and draw the Decision Trees (DT) Analysis which are undertaken and sampled by field investigation. These two activities cover the bulk of the quantitative survey research and qualitative survey research. The first, is an quantitative survey distributed to 520 individuals of different profession backgrounds who participate in improving the translation quality of linguistic landscape in new management mode. The second, is a series of feedbacks form faceto-face interviews with 80 informants of representatives of different levels, government departments and social fields at the national conference on linguistic landscape (Bin Lu, 2019). And this experimental research provides the implementation of pilot training program for language resources management in Chinese university foreign education, which cover the two fields, namely translation data resources of linguistic landscape and intelligent collaboration of Chinese university technology resources on monitoring quality system of linguistic landscape. The following are the data and its analysis:

\subsection{Reliability Statistics of Questionnaire}

The purpose of reliability analysis is to study whether the sample data is true and reliable, that is to say, whether the sample answers each question truthfully. The reliability of the sample data in this study is as follows: 
Table 1. Reliability Statistics of Questionnaire

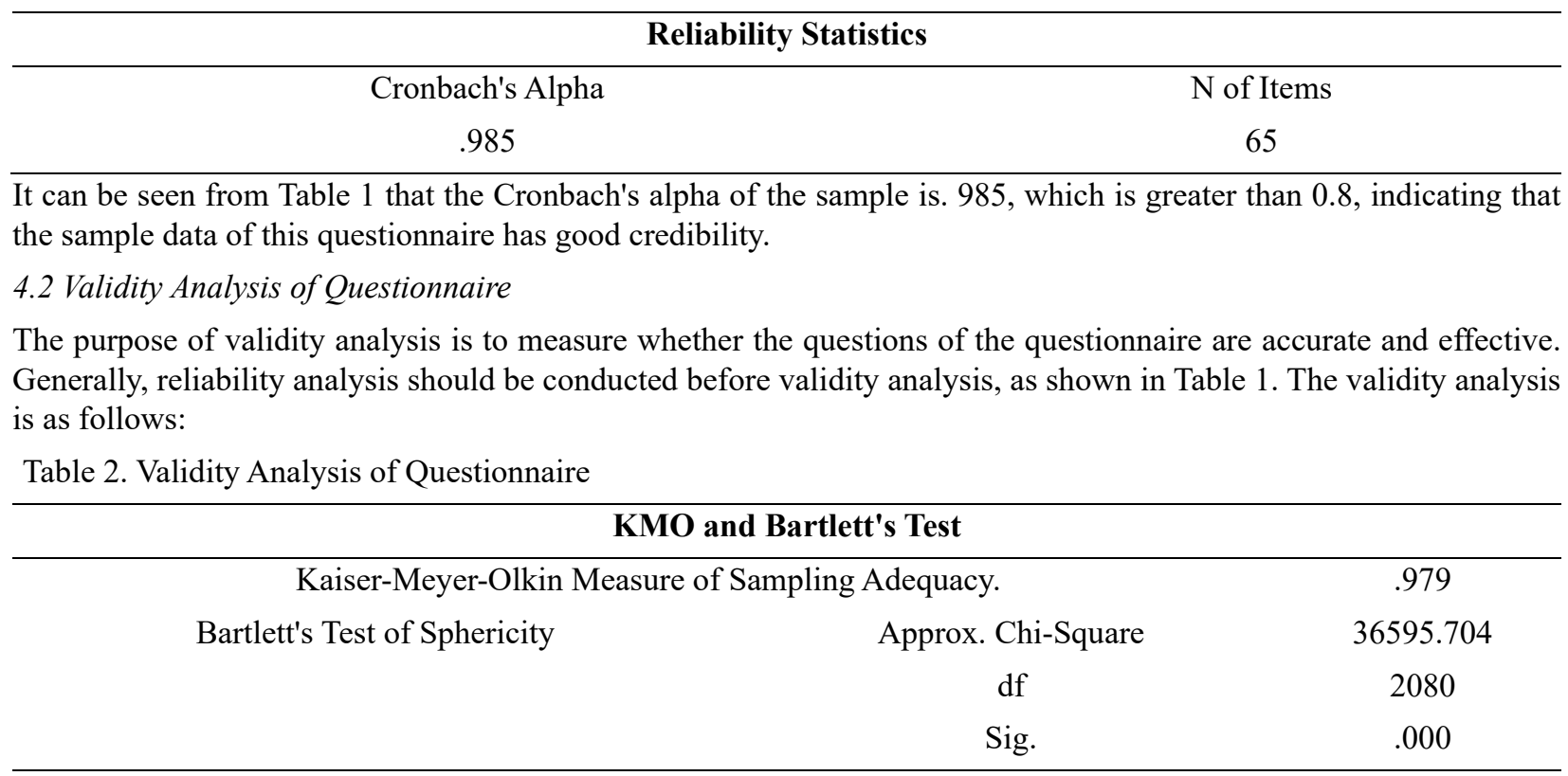

It can be seen from Table 2 that the Kaiser-Meyer-Olkin Measure of Sampling Adequacy is .979, which is greater than 0.8 , indicating that the questions of the questionnaire are accurate and effective.

\subsection{Correlation Analysis}

Table 3. Working Unit Distribution of Participants

\begin{tabular}{cccc}
\hline & Classification & Frequent & Percent \\
\hline Working unit & Government departments & 55 & $10.6 \%$ \\
& Local Enterprises & 49 & $9.4 \%$ \\
& Linguistic Landscape researchers & 101 & $19.4 \%$ \\
Local universities & 315 & $60.6 \%$ \\
& & 520 & $100 \%$ \\
\hline
\end{tabular}

Table 3 shows the working units distribution of the participants. According to the data of Table 3, it can be seen that the participants of government departments accounts for $10.6 \%$; the participants of local enterprises accounts for $9.4 \%$; the participants of landscape researchers accounts for $19.4 \%$; the participants of local universities accounts for $60.6 \%$. This study is to cover the different aspects which will be involved in this new management mode.

Table 4. Correlation between Working Unit and Total Score

\begin{tabular}{cccc}
\hline \multicolumn{3}{c}{ Correlations } & \\
\hline & Pearson Correlation & Working place & Total Score \\
\hline Working unit & Sig. (2-tailed) & 1 & \\
& $\mathrm{~N}$ & 520 & \\
Total Score & Pearson Correlation & $.105^{*}$ & \\
& Sig. (2-tailed) & .017 & 520 \\
*. Correlation is significant at the 0.05 level (2-tailed). & 520 & \\
\hline
\end{tabular}

Table 4 shows the characteristics of correlation between working unit and total score, and the correlation is 0.105 . In other words, Information from Table 4 revealed that there is less positive correlation between the people who have different working units and the total score towards city linguistic landscape. The research results from the test, therefore, 
accepted the earlier hypothesis which stated that there is less positive correlation between the people who have different working units and the total score towards city linguistic landscape. And the most important factor is the great concern for the translation quality of linguistic landscape of local city. The great concern of linguistic landscape translation quality does not come from the relevance of working unit but the deep responsibility on mission of local city development.

Table 5. Test of Homogeneity of Variance from Four Groups

\section{Test of Homogeneity of Variance}

\begin{tabular}{lccccc}
\hline & & Levene Statistic & df1 & df2 & Sig. \\
Total & Based on Mean & 2.433 & 3 & 516 & .064 \\
Score & Based on Median & 1.669 & 3 & 516 & .173 \\
& Based on Median and with adjusted df & 1.669 & 3 & 508.253 & .173 \\
& Based on trimmed mean & 2.390 & 3 & 516 & .068
\end{tabular}

The Table 5 above shows the results of variance homogeneity test for four groups of data. As the figures 1,2,3 and 4 above show that the four groups of data are roughly normal distribution (Sig.=0.064), which is greater than 0.05, indicating that the four groups of data have homogeneous variance.

Table 6. ANOVA of Participants' Total Score from Four Groups

\begin{tabular}{cccccc}
\hline \multicolumn{7}{c}{ ANOVA } \\
\hline & Total Score & & & \\
Sum of Squares & df & Mean Square & F & Sig. \\
Between Groups & 23297.184 & 3 & 7765.728 & 4.113 & .007 \\
Within Groups & 974350.747 & 516 & 1888.277 & & \\
Total & 997647.931 & 519 & & & \\
\hline
\end{tabular}

Table 6 shows the results of one-way ANOVA of the four groups. It can be seen from the table that there is a significant difference in the mean of the four groups of data ( $\mathrm{Sig} .=0.007<0.05$ ), which indicates that there are differences in the attitudes of participants who are in different working units towards linguistic landscape. And the groups which have significant differences in attitude need to be compared, as shown in the following table:

Table 7. Multiple Comparisons of Participants' Total Score

Dependent Variable: Total Score

\section{Multiple Comparisons}

\begin{tabular}{|c|c|c|c|c|c|c|c|}
\hline 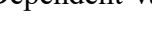 & & & & & & $95 \%$ Confi & ce Interval \\
\hline & & & Mean Difference & & & Lower & Upper \\
\hline & (I) 1. Working unit & (J) 1. Working unit & (I-J) & Std. Error & Sig. & Bound & Bound \\
\hline LSD & Government & Local Enterprises & 2.43265 & 8.53631 & .776 & -14.3375 & 19.2028 \\
\hline & departments & $\begin{array}{l}\text { Linguistic landscape } \\
\text { researchers }\end{array}$ & 6.51287 & 7.28204 & .372 & -7.7932 & 20.8190 \\
\hline & & Local universities & -9.41905 & 6.35034 & .139 & -21.8948 & 3.0567 \\
\hline & Local enterprises & $\begin{array}{c}\text { Linguistic } \\
\text { landscape researchers }\end{array}$ & 4.08022 & 7.56519 & .590 & -10.7821 & 18.9426 \\
\hline & & Local universities & -11.85170 & 6.67314 & .076 & -24.9616 & 1.2582 \\
\hline & $\begin{array}{l}\text { Linguistic } \\
\text { landscape } \\
\text { researchers }\end{array}$ & Local universities & $-15.93192^{*}$ & 4.96894 & .001 & -25.6938 & -6.1701 \\
\hline Bonferroni & Government & Local Enterprises & 2.43265 & 8.53631 & 1.000 & -20.1755 & 25.0408 \\
\hline & departments & $\begin{array}{c}\text { Linguistic } \\
\text { landscape researchers }\end{array}$ & 6.51287 & 7.28204 & 1.000 & -12.7734 & 25.7991 \\
\hline & & Local universities & -9.41905 & 6.35034 & .832 & -26.2377 & 7.3996 \\
\hline & Local enterprises & $\begin{array}{l}\text { Linguistic } \\
\text { landscape researchers }\end{array}$ & 4.08022 & 7.56519 & 1.000 & -15.9559 & 24.1164 \\
\hline & & Local universities & -11.85170 & 6.67314 & .458 & -29.5253 & 5.8219 \\
\hline & Linguistic & Local universities & $-15.93192^{*}$ & 4.96894 & .009 & -29.0920 & -2.7718 \\
\hline & $\begin{array}{l}\text { Landscape } \\
\text { researchers }\end{array}$ & & & & & & \\
\hline 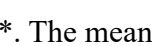 & erence is signifi & at the 0.05 level. & & & & & \\
\hline
\end{tabular}

Table 7 is a multiple comparison of the total scores of participants' attitudes towards linguistic landscape from four groups of different working units. It can be seen from the table that there is a significant difference between the 
personnel from linguistic landscape researchers and those from local universities (Sig. $<0.05)$. And the absolute value of the difference between local universities and the other three groups is the largest. Therefore, the total score of the attitude of the participants from local universities to linguistic landscape researcher is higher than that of the other three groups, which indicates that in addition to local universities should pay attention to the understanding and management of linguistic landscape research group, the other three types of working groups should also be paid attention to.

In the questionnaire of this study, there are three parts, namely the basic information of participants, a survey on social attitude toward behavior of quality monitoring of linguistic landscape (including survey toward individual understanding of linguistic landscape concept, study on social behavior of governmental departments related to linguistic landscape, linguistic landscape research of social behavior in relevant local universities, linguistic landscape researchers, and attitude toward translation quality of linguistic landscape of quality monitoring system.

In addition to the basic information of the participants may have a certain impact on the linguistic landscape, the questions may also have a certain correlation. As the previous part has analyzed the correlation between the participants' basic information such as gender, age, major and their conception to the linguistic landscape, this part will make a correlation analysis on the correlation between the five parts of questions, and the results are as follows: "Concept" refers to a survey of individual understanding of linguistic landscape concept; "government departments" refers to study on social behavior of tourism administration departments related to linguistic landscape and the construction of local city image; "local universities" refers to linguistic landscape programs involve the research of social behavior in relevant local universities; "local Enterprises" refers to linguistic landscape programs involve the research of social behavior of related enterprises; "Attitude toward translation quality of linguistic landscape on national tourism" refers to the study of quality monitoring indicators, such as translation quality, standard, evaluation, strategy and guarantee system of tourism linguistic landscape in following table.

Table 8. Correlation Analysis between Concept and Questions

\begin{tabular}{|c|c|c|c|c|c|c|}
\hline \multicolumn{7}{|c|}{ Correlations } \\
\hline & & Concept & $\begin{array}{l}\text { Government } \\
\text { departments }\end{array}$ & $\begin{array}{c}\text { Local } \\
\text { Universities }\end{array}$ & $\begin{array}{c}\text { Local } \\
\text { Enterprises }\end{array}$ & $\begin{array}{c}\text { Attitude toward } \\
\text { translation quality of } \\
\text { linguistic landscape }\end{array}$ \\
\hline Concept & $\begin{array}{l}\text { Pearson } \\
\text { Correlation } \\
\text { Sig. (2- } \\
\text { tailed) }\end{array}$ & 1 & & & & \\
\hline \multirow{3}{*}{$\begin{array}{l}\text { Government } \\
\text { departments }\end{array}$} & $\mathrm{N}$ & 520 & & & & \\
\hline & $\begin{array}{l}\text { Pearson } \\
\text { Correlation }\end{array}$ & $.675^{* *}$ & 1 & & & \\
\hline & $\begin{array}{l}\text { Sig. (2- } \\
\text { tailed) }\end{array}$ & .000 & & & & \\
\hline \multirow{3}{*}{$\begin{array}{c}\text { Local } \\
\text { universities }\end{array}$} & $\mathrm{N}$ & 520 & 520 & & & \\
\hline & Pearson & $.626^{* *}$ & $.789^{* *}$ & 1 & & \\
\hline & $\begin{array}{l}\text { Correlation } \\
\text { Sig. (2- } \\
\text { tailed) }\end{array}$ & .000 & .000 & & & \\
\hline \multirow{3}{*}{$\begin{array}{c}\text { Local } \\
\text { Enterprises }\end{array}$} & $\mathrm{N}$ & 520 & 520 & 520 & & \\
\hline & Pearson & $.579^{* *}$ & $.795^{* *}$ & $.859^{* *}$ & 1 & \\
\hline & $\begin{array}{l}\text { Correlation } \\
\text { Sig. (2- } \\
\text { tailed) }\end{array}$ & .000 & .000 & .000 & & \\
\hline & $\mathrm{N}$ & 520 & 520 & 520 & 520 & \\
\hline $\begin{array}{l}\text { Attitude toward } \\
\text { translation guality of }\end{array}$ & $\begin{array}{l}\text { Pearson } \\
\text { Correlation }\end{array}$ & $.549^{* *}$ & $.594^{* *}$ & $.750^{* *}$ & $.699^{* *}$ & 1 \\
\hline linguistic landscape & $\begin{array}{l}\text { Sig. (2- } \\
\text { tailed) }\end{array}$ & .000 & .000 & .000 & .000 & \\
\hline & $\mathrm{N}$ & 520 & 520 & 520 & 520 & 520 \\
\hline
\end{tabular}

Table 8 is the result of correlation analysis on the correlation between the questions. It can be seen from the Table 8 that there is a significant positive correlation between the participants' understanding of the concept of linguistic landscape and their attention to the social behavior of tourism administration departments related to linguistic 
landscape programs (Pearson Correlation $=0.675>0.6$ ); the correlation between the participants' understanding towards the concept of linguistic landscape programs involve the research of social behavior in relevant local universities is 0.626 , which is bigger than 0.6 . In other words, there is a significant positive correlation between them; the correlation between the participants' understanding towards the concept of linguistic landscape programs involve the research of social behavior of related enterprises is $0.579(0.579>0.4)$, that is to say, there is a significant positive correlation; the correlation between the participants' understanding towards the concept of linguistic landscape and the attitude toward translation quality of linguistic landscape programs is 0.549 , which is more than 0.4 , so there is a significant positive correlation.

In different part of questions, the correlation between the linguistic landscape programs involve the research of social behavior in relevant local universities and study on social behavior of government departments related to linguistic landscape programs is 0.789 ; the correlation between linguistic landscape programs involve the research of social behavior of related local enterprises and study on social behavior of government departments related to national tourism linguistic landscape is 0.795 ; the correlation between the attitude toward translation quality of linguistic landscape and social behavior of government departments related to linguistic landscape programs is 0.594 . In addition, the correlation between linguistic landscape programs involve the research of social behavior of related local enterprises and linguistic landscape programs involve the research of social behavior in relevant local universities is 0.859; the correlation between the attitude toward translation quality of linguistic landscape and linguistic landscape programs involve the research of social behavior in relevant local universities is 0.750 ; the correlation between the attitude toward translation quality of linguistic landscape and linguistic landscape programs involve the research of social behavior of related enterprises is 0.699 . That is to say, Government-Industry-University-Research management mode is of the system and monolithic, and this is main reason why it should be carried out new education management mode of society participants and invite all kinds of participants who are in great concern of translation quality of linguistic landscape in local city.

\subsection{Analytic Hierarchy Process Analysis}

This study is to realize the institutionalized, standardised and informationized mode of new education management in Chinese university language resources by surveying the different attitudes on linguistic landscape program which will improve the translation quality of local city image by the analytic hierarchy process (AHP) method. The focus, criteria and alternatives are described in the following data and figures.

Table 9. Responsibility and Authority Hierarchy of Linguistic Landscape Quality

\begin{tabular}{|c|c|c|}
\hline Number & $\begin{array}{c}\text { Program Participation } \\
\text { Role }\end{array}$ & Program Participation Function Description \\
\hline 1 & $\begin{array}{l}\text { Subject of Foreign Language } \\
\text { Major in r Local } \\
\text { Universities }\end{array}$ & $\begin{array}{l}\text { A. Enterprise managers and educators make overall plans for teaching practice } \\
\text { activities, curriculum models and assessment methods, implement specific } \\
\text { implementation plans, demonstrate and implement, summarize and report. } \\
\text { B. Teachers and students should study the school policy and deployment plan } \\
\text { seriously, strictly enforce all teaching links, ensure the quality and efficiency of } \\
\text { participating in the project, and take cultivating national talents as their own } \\
\text { duty. }\end{array}$ \\
\hline 2 & Government Departments & $\begin{array}{l}\text { A. Make overall planning and construction of cooperation office of colleges and } \\
\text { universities, make various preparations for intelligent diagnosis for famous 5A } \\
\text { scenic spots, and formulate coordinated development plans and implementation } \\
\text { plans for all parties of government, industry, university and research institute. } \\
\text { B. Employ linguistic landscape expert team for on-site assessment and } \\
\text { evaluation. } \\
\text { C.Release annual analysis report of linguistic landscape quality monitoring } \\
\text { system. } \\
\text { D. Improve the quality revision of tourist attractions signs. }\end{array}$ \\
\hline 3 & $\begin{array}{lr}\text { Linguistic } & \text { Landscape } \\
\text { Quality } & \text { Monitoring } \\
\text { Enterprise Team } & \end{array}$ & $\begin{array}{l}\text { A. Overall planning for the construction of linguistic landscape Big Data } \\
\text { monitoring system. } \\
\text { B. Make overall arrangements for teachers and students to participate in } \\
\text { linguistic landscape quality monitoring data collection. }\end{array}$ \\
\hline 4 & $\begin{array}{l}\text { Linguistic Landscape Expert } \\
\text { Team }\end{array}$ & $\begin{array}{l}\text { A. Make overall arrangements for teachers and students to participate in the } \\
\text { design and process of the integration of linguistic landscape, teaching and } \\
\text { evaluation. } \\
\text { B. Training teachers and students to carry out linguistic landscape data } \\
\text { collection work. } \\
\text { C. Discussion on key issues of linguistic landscape quality monitoring. }\end{array}$ \\
\hline
\end{tabular}




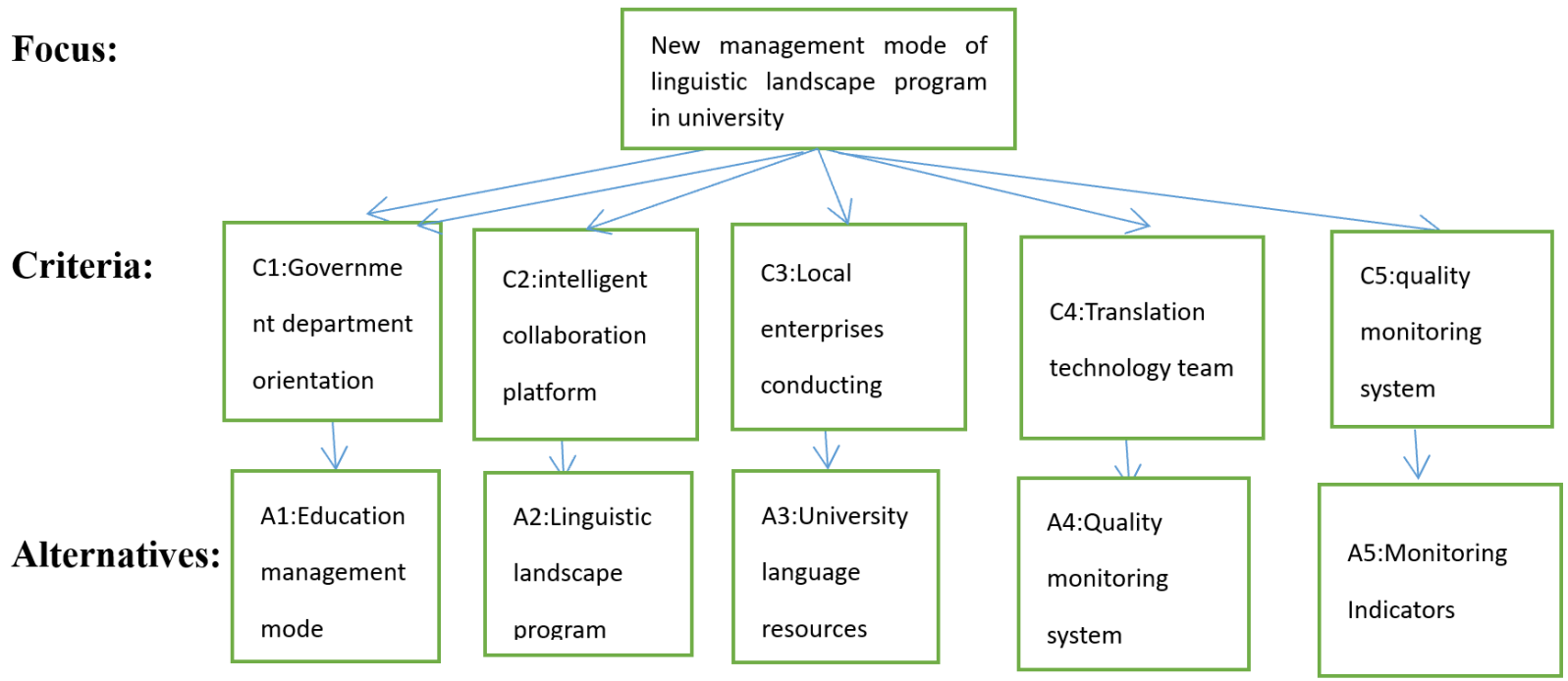

Figure 6. Analytic Hierarchy Process Analysis of New Management Mode

\subsection{Decision Tree Analysis}

The mode of decision tree is constructed based on the data of participants who are involved in this linguistic landscape program of university language resources, so as to identify the priority relationship of the data categories of government departments. And the mode can provide an operational method for the university's carrying out the linguistic landscape program of intelligent collaboration platform.

For foreign language education managers in universities, when the cooperation efficiency of Government-IndustryUniversity-Research is high, the estimated benefit is reflected in the improvement of talent training, professional quality and image; in terms of management, with the establishment of linguistic landscape quality detection system, the training scheme and training efficiency will be improved. The estimated risk is shown in the real implementation effect on how to coordinate the inherent concept with the coordinated development of diversification.

When the efficiency of Government-Industry-University-Research mode is low, the estimated benefit performance is that the talent training mode and image construction of local city are initially improved, the estimated risk is that the talent training mode is chaotic and the professional quality is still to be improved; the image of local university and local city will lead to the reduction of public professional trust, which will have a negative impact. In education management level, the training program on quality monitoring system of linguistic landscape will be confused, resulting in low training efficiency, and finally lead to the waste of human, material and financial resources. The decision tree analysis is as the following: 


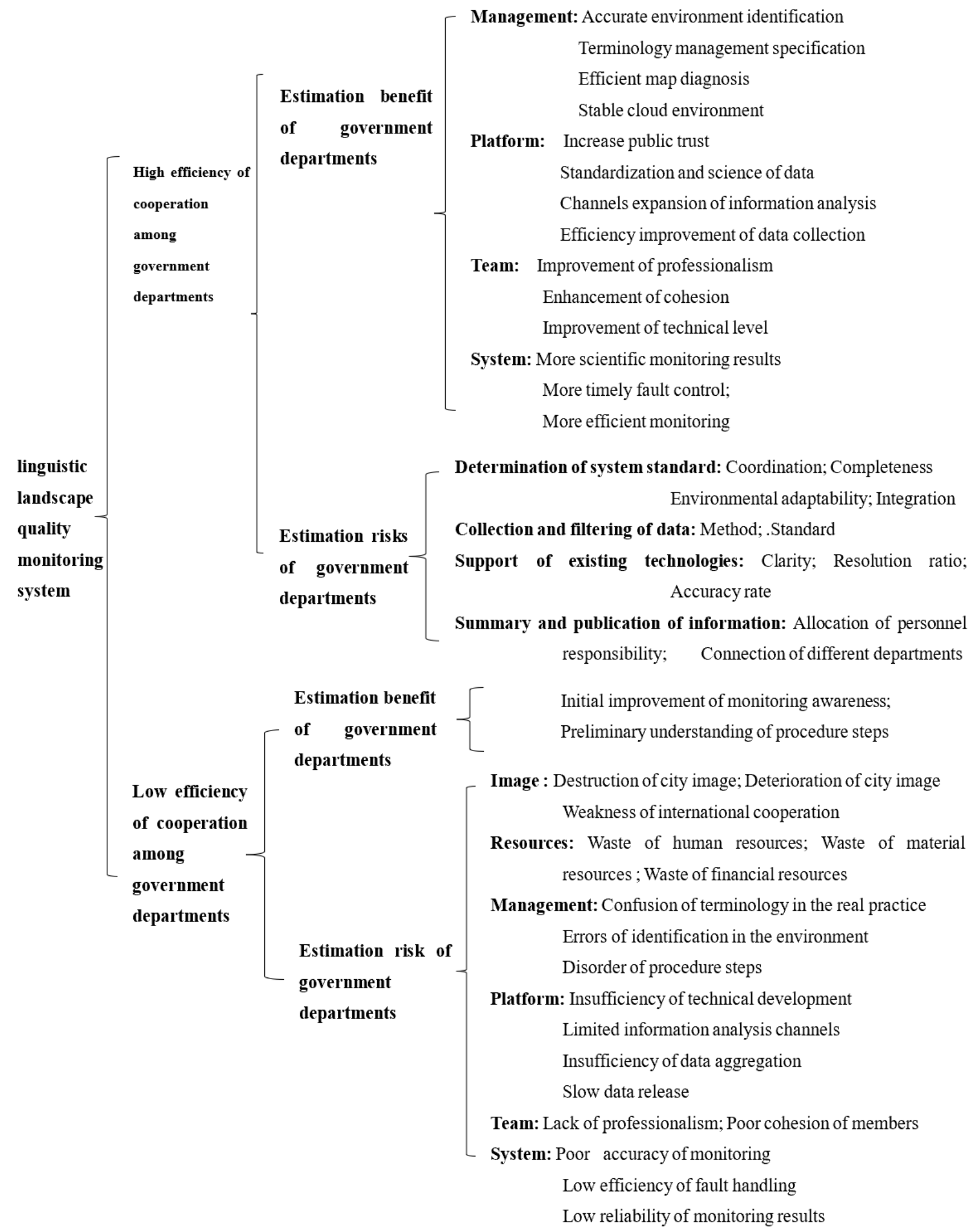

Figure 7. Decision Tree Analysis of Government Department 
The first description is the analysis of government's estimated benefit or revenue and estimated risk. If the government departments have high efficiency in the construction of quality monitoring system on linguistic landscape, and the estimated benefits is embodied in management, platform, team and system levels. It is likely to construct the SOP mode which is the main contribution of pilot research and form the standardized procedure. In terms of management, the construction of quality monitoring system on linguistic landscape can make the environment of the scenic spot be identified accurately, and the use of terms in the scenic spot can be more standardized. And with the development and improvement of science and technology, intelligent diagnosis and Big Data storage and analysis are compared with traditional artificial monitoring, recognition and analysis, to a large extent, are more objective, scientific and efficient, and more effective on efficient mapping diagnosis and more stable Cloud Computing access environment. The construction of quality monitoring system on linguistic landscape can be more scientifically monitor problems such as improper use of scenic area environmental terms. Therefore, on the quality monitoring system platform, it can increase the public's trust on collaborative program. Because of the acquisition of Big Data and the establishment of database, it can make the data arrangement more standardized and scientific, broaden the information analysis channels, and at the same time, the information collection and publication efficiency can also be improved and get the corresponding promotion.

For the relevant teams of government quality monitoring on linguistic landscape, the quality monitoring system on linguistic landscape makes it more professional, the technical level be improved, and the cohesion of the team can also be better organized and exercised. For the system, the construction of the detection system can make the monitoring results more scientific, and the faults in the scenic spot can be adjusted and controlled timely and efficiently. Any investment is a combination of benefit and risk. Even if the government departments and all participants cooperate efficiently, it is no exception. The most prominent problem and predicted risk in the construction of quality monitoring system on linguistic landscape lies in how to determine the standard of the system, whether the existing technology can meet the requirements of the system, how to coordinate the collection and selection of data, and how to coordinate the collection and publication of these information. The determination of system standards should reflect the characteristics of coordination, integrity, environmental adaptability and integrity. In addition, how to set the standards of data collection and screening and what methods to adopt can be carried out scientifically and effectively; whether the clarity and accuracy of the existing technology can adapt to and meet the requirements of the current quality problem of linguistic landscape, applied construction of quality monitoring system and other issues can be dealt with effectively or not is the potential risk. 


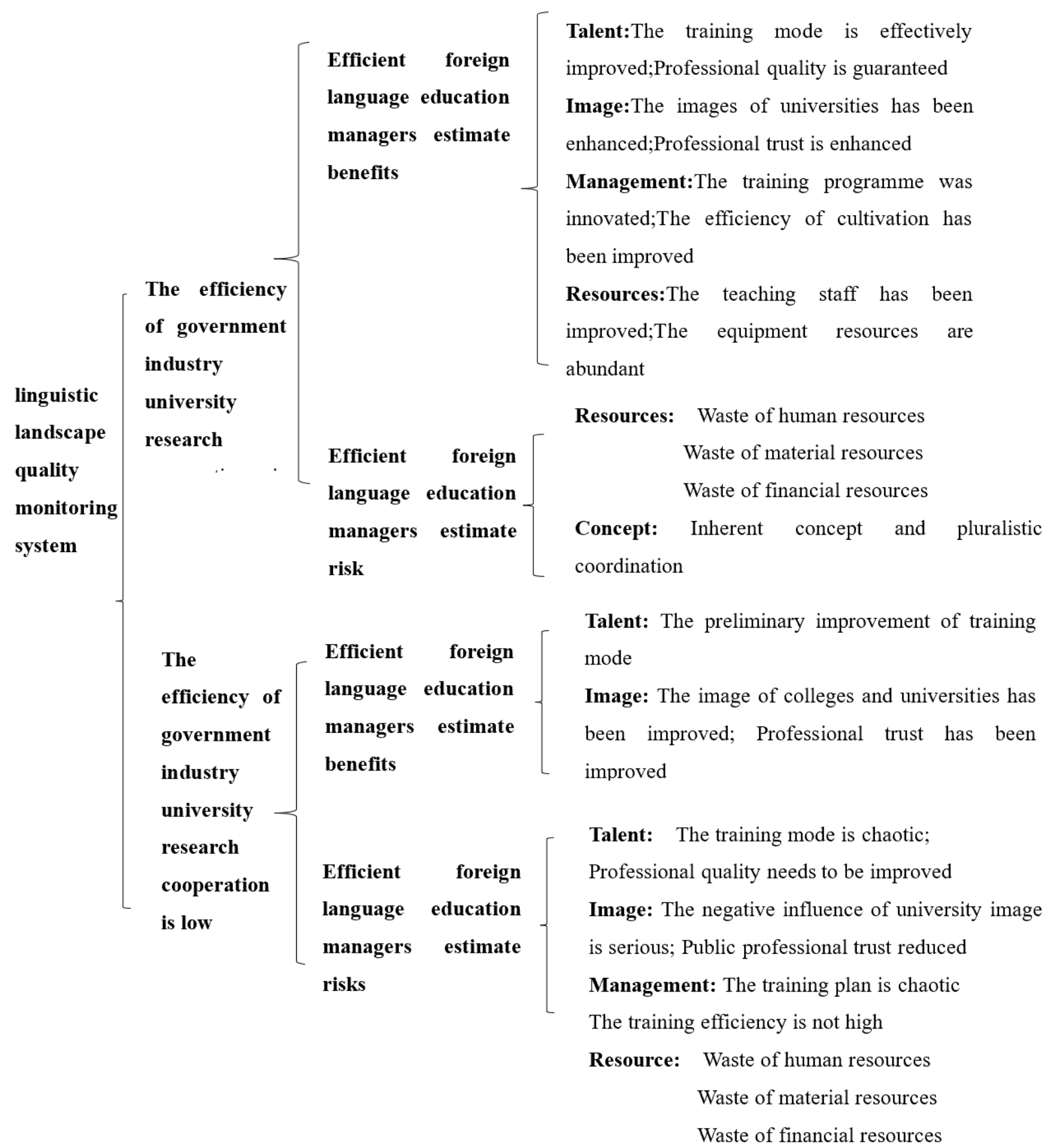

Figure 8. Decision Tree Analysis of Local Universities 
For foreign language majors in universities education management, when the cooperation efficiency of GovernmentIndustry-University-Research mode is high, the estimated benefit is reflected in the improvement of talent training, professional quality and image; in terms of management, with the establishment of linguistic landscape quality detection system, the training scheme and training efficiency will be improved. The estimated risk is shown in how to coordinate the inherent concept with the coordinated development of diversification.

When the efficiency of Government-Industry-University-Research management mode is low, the estimated benefit performance is that the talent training mode and image are initially improved, the estimated risk performance is that the talent training mode is chaotic and the professional quality is still to be improved; the image will lead to the reduction of public professional trust, which will have a negative impact. In management, the training program will be confused, resulting in low training efficiency, and finally lead to the waste of human, material and financial resources.

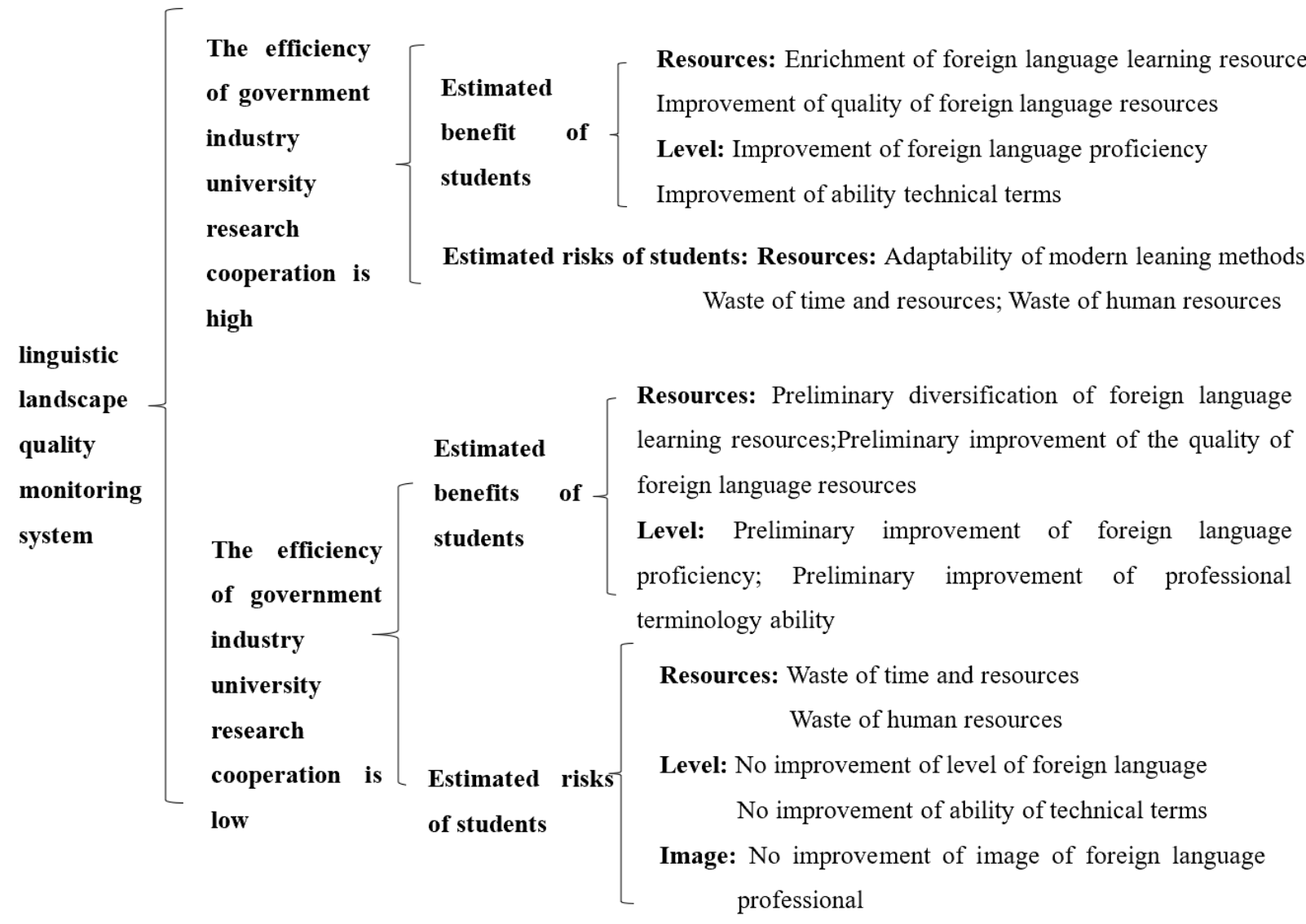

Figure 9. Decision Tree Analysis of University Students

The construction of quality detection system on linguistic landscape for university student who are in foreign language majors is beneficial, especially on the perspective of soft power production with high efficiency. For students, estimated benefits will be the soft power on professional talents on this collaboration platform of quality monitoring system, material resources and financial resources integration and utilitarian. At the same time, due to the support of various resources in university language resources, it is also to improve students' foreign language ability and competence level, and the language ability of quality monitoring system on linguistic landscape, the establishment of the language problem will be improved. The construction of quality monitoring system on linguistic landscape, the establishment of linguistic landscape can be largely monitoring and timely solve the problem of translation quality on linguistic landscape. For students, their traditional way of textbook learning will be improved and the adaptability of the challenge in modern learning style is relatively high developed, the education quality will be improved too. 


\section{Main Findings and Conclusion}

From data analysis and decision tree analysis above, the main findings of this experimental research are following:

\subsection{The Experimental Research of Educational Management Mode}

\subsubsection{Dominant Attitude and Leading Role}

The turning of participation consciousness, especially the active attitude of governmental teams in language data and technology resources on linguistic landscape program are the most important factor in this education management research, it will make great links among the different team and regulate each activities for the internationalization of smart city construction, the language technology resources will benefit both for university and local city.

\subsubsection{Reconsideration Decision-making and New Data Resources}

The new resource development of data resources construction will have great influence on the reconsideration of decision-making and new language policy, this new kind of data resources and intelligent technology by carrying out this linguistic landscape program will benefit the new soft power of society and local city.

\subsubsection{Construction Strategy and Social Participation}

The applied strategy of participation community and technology development community of linguistic landscape program are the main focuses in different background participants and the construction method and quality assurance of this new language data technology and collaboration platform are the main decisive factors which can attract different participant teams to join together to developing new soft power for local city or waste the society resources.

\subsubsection{Multi-platform Technology and Society Data Resources Management}

The multi-platform technology development and society data resources management are the most difficulty factor in different participants, but at the same time, they are the new technical section which will start the intelligent technology development and Big Data resources management. The university education management will benefit not only for the students of foreign language majors but also for intelligent technology majors and data resources majors, thus make the diversity development of new society data resources management.

\subsection{The Experimental Research of Linguistic Landscape Program}

\subsubsection{Pilot Model of University Program Management}

The foreign language education in Chinese university should carry on language resources programs which is not only benefit to teachers and students in university, but also benefit to the development of society and local city. So the new pilot management mode of university language program is available to find the reasons why linguistic landscape policies or guidelines' revision are difficult to implement. The improvement of foreign language education quality of linguistic landscape research can also use questionnaires, interviews, etc. to understand the motivation of landscape researchers, readers' attitudes and feelings. Linguistic landscape research on quality monitoring system can be shared by the different local cities if the analysis unit or quality monitoring standards can be reached an common agreement. This research make the common understanding of different social groups to construct new multi-platform on quality monitoring system of linguistic landscape.

\subsubsection{Multi-platform Technology of Linguistic Landscape programs}

Foreign language education management should connect with the technological development and construction intelligent collaboration of multi-platform which can combine the university technology resources and society. This is not only the applied management methods, but also is the new technological development mode of language resources production. More interdisciplinary research, multi-empirical research, data processing and language technology are required in this experimental research of linguistic landscape programs. Interdisciplinary research should broaden the research scope and build a specific corpus for the collected corpus and quality corpus. The establishment of specific Big Data can make linguistic landscape research corpus diversified and match other linguistic technological research easier, it will helpful to learn from other disciplines of research theory, research methods, especially from the computer data processing and computer technology. Linguistic landscape programs cannot only be considered as belonging to a certain discipline or applicable to a certain theory, which will not only limit the development of linguistic landscape research, but also it will become the starting point of data resources construction of Smart City. 


\subsubsection{Multi-platform Cooperation of Linguistic Landscape}

Foreign language education management should connect with the new collaboration platform and complicated evaluation of linguistic and technology subjects. With the survey on attitudes of improving quality on linguistic landscape, this research apply for the multi-platform cooperation for collaboration innovation. The different social groups will make different concerns. For example, the government officials pay more attention to the images of local city and local culture internationalization, local companies think about their international brand, local universities cares about the educational management reform of talents cultivation and new language data resources development, try to find new applied platform of language service quality. After the survey, these common understanding on improving the translation quality of linguistic landscape, all the group is engaged in seeking common ground while reserving differences and construct the multi-platform to develop the new technological and multimodal research of social data resources. And from the feedbacks of Likert scale, all the different groups from government departments, local companies, local universities and social individuals have one common understanding on the same questions, namely, all of them cannot find available channel or platform to take part in improving the quality of linguistic landscape. That means the government departments should design the next procedure and planning new implementation policy on linguistic landscape program, and think about how to use these great human resources effectively.

Above all, the foreign language education of Chinese university need the new management mode which can lead the major to the bright future in this new time. The university language resources is very important new production force and new resource which is another symbol of integrated solid. The questions and doubts on foreign language students' competence, can be solved by the new education experiment research on language data technology. The government, enterprises, research institutes and universities cooperate with each other and form the language data team. These linguistic landscape program can adjust the out-of-date cultivation management and evaluation mode after experimental survey research. Among this Government-Industry-University-Research mode, if the four teams cooperate with each other deeply and efficiently, the estimated benefit is greater than the estimated risk, which can be reflected in resources, systems and management respectively. Because of the government's attention to the activities on the improvement of linguistic landscape quality and its monitoring system, the different participants will not only be broadened in the access to technology development with financial support, but also can make the management development of technology faster and more efficient; in the monitoring system, quality monitoring of multi-platform in the use of intelligent terminology can be scientifically and objectively led and guided, and the language data resource programs both in university and society can be more standardized, more scientific and efficient in the intelligent diagnosis development of Smart city.

\section{Acknowledgements}

We are grateful for the financial support from Social Science Foundation of Ministry of Education (No.17YJA740032) and He'nan Social Sciences Planning Project (No.2018BYY018).

\section{References}

An, M. M., Fan, X. M., \& Cai, H. Y (2020). Research on intelligent cooperative control of traffic lights based on fog computing and reinforcement learning. Application Research of Computers, (2), 465-469.

Chai, R. (2020). Design and Implementation of Library Bibliographic Collaborative Intelligent Recommendation System. Microcomputer Applications, 36(4), 133.

Chen, C. H., \& Zhong, H. (2020). Key to digital transformation: intelligent collaboration, informatization and intellectualization, (11).

Chen, S., \& Wu, Q. X. (2020). Distribution network information physics system based on edge cloud intelligent collaboration. Journal of Beijing Information Science\&Technology University, (1), 95-100.

Gao, Y., \& Huang, R. H. (2017). Interpretation and Enlightenment of 2017 New Media Alliance China Higher Education Technology Outlook: Horizon Project regional report. Audio visual education research, 38(4), 15-22.

Geoff, M. (2018). Big Mind: How Collective Intelligence Can Change Our World. Princeton University Press. https://doi.org/10.1515/9781400888511

Gong, Z., Yang, A. H., \& Zhao, H. K. (2014). Development and application of surgical robot. China medical education technology, 28(3), 273-277.

Liang, S., \& Wang, Y. M. (2016). Research on the supply- side transformation of sports manufacturing industry under the horizon of "Internet-L"-the development and application of 020 business model. Journal of Sports and Science, (4), 36-41. 
Lu, B. (2019). A Survey on Attitudes towards Quality Monitoring Systems of Linguistics Landscape International Journal of Comparative Literature \& Translation Studies, 7(3), 87-108. https://doi.org/10.7575/aiac.ijclts.v.7n.3p.87

Matt, R., Gambrell, D., \& Simone, B. (2020b). Using Collective Intelligence to Solve Public Problems. Nesta, 83-87.

Meng, H. H. (2020). Research on the collaborative development path of artificial intelligence and librarians. Library work research, 4(9), 290.

Ryan, M., The GovLab, \& Gambrell, D. (2020a). Using Collective Intelligence to Solve Public Problems, Nesta, 12.

Xie, F., \& Liu, Y. R. (2019). Design and implementation of Mobile Intelligent Collaborative Office System Based on wechat public platform. Mobile application, (12), 73-75.

Xu, Y. (2020). Efficient upgrade of intelligent cooperative sorting and transmission. Products View, 1.

Yang, L. (2017). The change of cognition, thinking and behavior by artificial intelligence. Exploration and contention, (10), 16-18.

Zhang, C., \& Fan, X. Y. (2019). Edge computing enabled smart grid. Big data, 5(02), 64-78.

Zhou, X., \& Li, T. X. (2020). Research on future space-ground integrated information network based on edgeintelligence collaborative. Telecom Science, (7), 71-79.

Zhu, Y. H., \& Liu, H. (2019). Human computer collaborative intelligence hierarchy and new prospect of teachers' professional form in the era of intelligent education. Audio Visual Education Research, 1, 104.

\section{Copyrights}

Copyright for this article is retained by the author(s), with first publication rights granted to the journal.

This is an open-access article distributed under the terms and conditions of the Creative Commons Attribution license (http://creativecommons.org/licenses/by/4.0/). 